\title{
Controlled trial of continuous inflating pressure for hyaline membrane disease
}

\author{
G. M. DURBIN, N. J. HUNTER, N. MCINTOSH, E. O. R. REYNOLDS, \\ and P. D. WIMBERLEY \\ From the Department of Paediatrics, University College Hospital and Medical School, London
}

Durbin, G. M., Hunter, N. J., McIntosh, N., Reynolds, E. O. R., and Wimberley, P. D. (1976). Archives of Disease in Childhood, 51, 163. Controlled trial of continuous inflating pressure for hyaline membrane disease. A controlled trial of elective intervention with continuous inflating pressure (CIP) was performed in infants with severe hyaline membrane disease who weighed more than $1000 \mathrm{~g}$ at birth. Infants entered the trial if their arterial oxygen tension $\left(\mathrm{PaO}_{2}\right)$ fell below $60 \mathrm{mmHg}$ while breathing a fractional inspired oxygen concentration $\left(\mathrm{F}_{\mathrm{r}} \mathrm{O}_{2}\right)$ greater than 0.95 . 11 out of 12 infants in the CIP-treated group and 10 out of 12 in the control group survived. 7 treated and 6 control infants required mechanical ventilation. When CIP was started the $\mathrm{PaO}_{2}$ of the treated infants increased, and they breathed high concentrations of oxygen for a significantly shorter period than the control infants. During the 31-month duration of the trial 107 other infants with severe hyaline membrane disease were admitted who did not meet the criteria for entry to the trial. 37 survived after breathing high concentrations of oxygen $\left(\mathrm{F}_{\mathrm{x}} \mathrm{O}_{2}>0 \cdot 60\right)$ spontaneously without any ventilatory assistance, and the remaining 70 infants were already being ventilated on their arrival in the unit, usually because they had required mechanical ventilation during transfer from other hospitals. The neonatal survival rate for those infants born in this hospital during the study period was $88 \%$ (50 out of 57 infants) and for those referred from other hospitals it was $69 \%$ (51 out of 74 infants). The maximum further increase in overall survival rate that might have been achieved in our population of infants if CIP had been initiated very early in the course of the illness was $5 \%$-i.e. from $77 \%(101 / 131)$ to $82 \%(107 / 131)$.

In 1971, Gregory et al. published their important study showing that if infants with hyaline membrane disease (HMD) breathed spontaneously against a continuous positive airway pressure (CPAP) applied down an endotracheal tube or from a pressurized head-box, lung inflation improved and arterial oxygen tension $\left(\mathrm{PaO}_{2}\right)$ increased. Since then various methods for applying CPAP have been devised, using a face mask (Rhodes and Hall, 1973), a plastic bag over the head (Barrie, 1973), and nasal cannulae (Kattwinkel et al., 1973; Caliumi-Pellegrini et al., 1974). Other authors (Chernick, and Vidyasagar, 1972), instead of applying a positive pressure to the interior of the lung, apply a negative pressure around the chest, which has the same effect as CPAP in promoting lung inflation. This technique is usually called continuous nega-

Received 25 June 1975. tive pressure (CNP). Because both CPAP and CNP have as their object the maintenance of adequate alveolar inflation, we have called them continuous inflating pressure (CIP). All those who have used CIP are agreed that it is effective in raising $\mathrm{PaO}_{2}$ in $\mathrm{HMD}$; and many have inferred that early intervention with CIP would reduce the number of infants requiring mechanical ventilation and lead to an increase in survival rate. Only two controlled trials have, however, compared the efficacy of CIP with previously available methods for managing the illness. Rhodes and Hall (1973), who used a face mask, showed a decrease in mortality significant at the $5 \%$ level but only in infants weighing more than $1500 \mathrm{~g}$. Fanaroff et al. (1973), who used CNP, did not set out to show any difference in survival but found that treated infants reached defined criteria for failure of therapy less often than did controls. In both these trials the 
point of entry was a $\mathrm{PaO}_{2}<60 \mathrm{mmHg}$, when the infant was breathing a fractional inspired oxygen concentration $\left(\mathrm{F}_{1} \mathrm{O}_{2}\right)>0.5$ (Rhodes and Hall, 1973), or $>0 \cdot 7$ (Fanaroff et al., 1973).

We have used very high concentrations of oxygen-up to an $\mathrm{F}_{\mathrm{I}} \mathrm{O}_{2}$ of 1.00 if necessary-in the management of infants with HMD before contemplating ventilatory support, and have used mechanical ventilator techniques which minimized trauma to the lung if the infant could not sustain adequate gas exchange (Herman and Reynolds, 1973; Blake et al., 1973; Reynolds, 1974). Because we were uncertain whether elective intervention with CIP had any advantages over our previous methods of management, a controlled trial has been carried out, the results of which are reported here. Infants entered the trial if their $\mathrm{PaO}_{2}$ fell below $60 \mathrm{mmHg}$ while they were breathing an $\mathrm{F}_{\mathrm{I}} \mathrm{O}_{2}>0.95$, and CIP was applied either as CPAP via an endotracheal tube or as CNP. In order to find out whether earlier intervention might have led to a higher survival rate, data from all infants with severe HMD admitted during the $2 \frac{1}{2}$-year duration of the trial have also been analysed.

\section{Methods}

Definition of 'severe' HMD. Infants were classified as suffering from 'severe' HMD if they fulfilled previously defined criteria (Reynolds and Taghizadeh, 1974), and had the usual clinical and radiological features of the illness, together with $\mathrm{PaO}_{2}<90 \mathrm{mmHg}$ while breathing an $\mathrm{F}_{1} \mathrm{O}_{2}>0 \cdot 60$.

General management. The general management of infants with HMD admitted during the study period, which began on 1 June 1972, was as previously described (Reynolds, 1975). They were nursed in incubators or under radiant heat sources. Umbilical arterial catheters with the tips sited at the level of the 2nd to 4th lumbar vertebrae were used for arterial blood sampling. After removal of the catheter at about 4 days of age, and in cases where a catheter could not be inserted, peripheral arterial sampling was used. Infants entering the controlled trial all had arterial catheters in situ. Measurements of $\mathrm{PaO}_{2}, \mathrm{PaCO}_{2}, p \mathrm{H}$, and base excess (BE) were made at intervals dependent upon the clinical condition of the infant, and these were rarely more than 4 hours during the acute stage of the illness. Measurements were performed immediately the blood samples had been obtained, using Radiometer equipment (Adamson et al., 1969). Breathing and heart rate were continuously monitored, and arterial blood pressure was monitored when indicated by attaching a pressure transducer to the arterial catheter. Continuously recording intra-arterial oxygen electrodes (Conway et al., 1976) were also used during the latter half of the study period. Adequate amounts of fluid and calories were supplied from the time of arrival in the unit, usually by a combination of nasogastric tube feeding and intravascular infusions of $10 \%$ dextrose and electrolytes. Total parenteral nutrition (Shaw, 1973) was used if caloric requirements could not be met in any other way. Intravenous injections of $5 \%$ sodium bicarbonate solution (up to $5 \mathrm{ml}, 3 \mathrm{mmol}$ ) were given if a very severe hypoxic episode occurred, and injections were given slowly. Blood glucose, bilirubin and electrolyte levels, and coagulation status were measured as required and appropriate therapy given. Cultures from the tracheal aspirates of intubated infants were taken daily and antibiotics (gentamicin and penicillin) given if necessary. The infants were cared for by experienced nurses who were trained in resuscitation.

Trial. Spontaneously breathing infants with severe HMD who weighed $>1000 \mathrm{~g}$ at birth and who had not previously required ventilatory assistance other than that needed for resuscitation at birth were eligible for entry into the trial. 24 sealed and shuffled envelopes were prepared in order to assign the infants into two groups, and an envelope was opened if an infant's $\mathrm{PaO}_{2}$ fell $<60 \mathrm{mmHg}$ when breathing an $\mathrm{F}_{\mathrm{r}} \mathrm{O}_{2}>0.95$ for at least 15 minutes. When 'CIP' was drawn, this was immediately set up. If it was judged that the infant's condition was worsening rapidly, CIP was delivered as CPAP via an oroendotracheal tube in a manner similar to that described by Gregory et al. (1971). If the infant did not seem to be so seriously ill, particularly if his gestational age was $>33$ weeks, CNP was applied with a Draeger Pulmarca negative pressure tank. Whichever method was used, a transpulmonary pressure of 8-10 $\mathrm{cmH}_{2} \mathrm{O}$ was initially used, and sufficient oxygen in the inspired gas was administered to give a $\mathrm{PaO}_{2}$ of about $65 \mathrm{mmHg}$. If the infant's $\mathrm{PaO}_{2}$ improved, both CIP and $\mathrm{F}_{\mathrm{r}} \mathrm{O}_{2}$ were progressively decreased, and CIP was stopped when the $\mathrm{PaO}_{2}$ was adequate at zero transpulmonary pressure in $\mathrm{F}_{\mathrm{I}} \mathrm{O}_{2}$ of $0.5-0.7$. If, on the other hand, the infant's oxygenation deteriorated and his $\mathrm{PaO}_{2}$ fell below $40 \mathrm{mmHg}$ when he was breathing an $\mathrm{F}_{1} \mathrm{O}_{2}$ of $1 \cdot 00$, CIP was sometimes raised as high as $12 \mathrm{cmH}_{2} \mathrm{O}$ (and once transiently to $14 \mathrm{cmH}_{2} \mathrm{O}$ ) but no higher. Mechanical ventilation was started when the $\mathrm{PaO}_{2}$ fell below $35 \mathrm{mmHg}$ or if the infant seemed likely to collapse, as judged by the presence of peripheral vasoconstriction, gasps, a slowing respiratory rate, or a slowing heart rate. A Draeger Spiromat 661 or 662 ventilator was used as previously described (Blake et al., 1973; Reynolds, 1975).

Infants assigned to the control group were not treated by CIP but they were managed in the same way in all other respects as the infants in the CIP group. Infants in both groups requiring mechanical ventilation were often weaned from the ventilator with CPAP.

\section{Results}

Composition of $\mathrm{CIP}$ and control groups, and outcome. The trial took 31 months to complete. The 24 infants entered in it were consecutively admitted infants who fulfilled the criteria for entry. 
Clinical data and the outcome for the two groups of 12 infants are given in Table I, together with data from the whole population of infants with severe HMD admitted during the study period. The groups in the trial were comparable in composition. At entry to the trial (Table II) the mean $\mathrm{PaCO}_{2}$ of the control group was significantly higher and the mean $p \mathrm{H}$ lower than in the CIP group, but the $\mathrm{PaO}_{2}$ and base excess were not significantly different. The number of infants requiring mechanical ventilation, and the number who survived, were similar in the two groups (Table III).

Effect of CIP. One infant assigned to the CIP group deteriorated as she was being positioned in the negative pressure chamber: she was therefore intubated and mechanically ventilated. 8 of the remaining 11 infants were treated by CPAP and 3 by CNP. The mean values for blood gas tensions and acid-base status obtained before and within 50 minutes after starting CIP are given in Table II. One infant who was difficult to intubate received $5 \mathrm{ml}(3 \mathrm{mmol} / \mathrm{l})$ of $5 \%$ sodium bicarbonate solution intravenously while CPAP was being set up. The only significant change when CIP was started was an increase in $\mathrm{PaO}_{2}$.

The total length of time that CIP was used in the infants in the CIP group was $39 \cdot 4 \pm$ SEM 6.9 hours. The mean transpulmonary pressure used was $6 \cdot 2 \pm 0 \cdot 5 \mathrm{cmH}_{2} \mathrm{O}$, and the mean maximum pressure $9 \cdot 9 \pm 0.6 \mathrm{cmH}_{2} \mathrm{O}$. The 7 infants who required mechanical ventilation received between 1 and 13 hours (mean 6 hours) of CIP before ventilation became necessary and 4 of them received CIP afterwards for between 12 and 32 hours (mean 16 hours). 3 infants in the control group were treated with CPAP for between 12 and 76 hours during weaning from mechanical ventilation. In both

TABLE I

Clinical data from the control group of infants, the CIP-treated group, other infants with severe HMD admitted during the trial period, and the total population of infants with severe HMD

\begin{tabular}{|c|c|c|c|c|}
\hline & Control & CIP & Other infants & All infants \\
\hline $\begin{array}{l}\text { No. of infants } \\
\text { UCH } \\
\text { Referred } \\
\text { Total } \\
\text { Birthweight (g) } \\
\text { Gestational age (w) } \\
\text { Sex ratios (boys :girls) } \\
\text { Age at entry to trial (h) } \\
\text { Survived >28 days (no. of infants) } \\
\text { UCH } \\
\text { Referred } \\
\text { Total }\end{array}$ & $\begin{array}{c}10 \\
2 \\
12 \\
1922 \pm 169 \\
32 \cdot 7 \pm 0 \cdot 9 \\
6: 6 \\
30 \cdot 3 \pm 6 \cdot 1 \\
9 \\
1 \\
10(83 \%)\end{array}$ & $\begin{array}{c}7 \\
5 \\
12 \\
2160 \pm 176 \\
33 \cdot 5 \pm 0 \cdot 8 \\
7: 5 \\
28 \cdot 2 \pm 3 \cdot 7 \\
7 \\
4 \\
11(92 \%)\end{array}$ & $\begin{array}{c}40 \\
67 \\
107 \\
1910 \pm 64 \\
32 \cdot 5 \pm 0 \cdot 3 \\
61: 46 \\
- \\
34 \\
46 \\
80(75 \%)\end{array}$ & $\begin{array}{c}57 \\
74 \\
131 \\
1928 \pm 57 \\
32 \cdot 5 \pm 0 \cdot 3 \\
75: 57 \\
- \\
50(88 \%) \\
51(69 \%) \\
101(77 \%)\end{array}$ \\
\hline
\end{tabular}

Mean values \pm 1 SEM are given.

\section{TABLE II}

Fractional inspired oxygen concentration $\left(\mathrm{F}_{1} \mathrm{O}_{2}\right)$, aortic arterial oxygen tension $\left(\mathrm{PaO}_{2}\right)$, carbon dioxide tension $\left(\mathrm{PaCO}_{2}\right), \mathrm{pH}$, and base excess $(\mathrm{BE})$ at entry to trial in control and CIP-treated groups. Values obtained just before, and just after starting CIP are also shown

\begin{tabular}{|c|c|c|c|c|}
\hline & Control & & CIP & \\
\hline & Entry & Entry & Before CIP & After CIP \\
\hline $\begin{array}{l}\text { No. of infants } \\
\mathrm{F}_{1} \mathrm{O}_{2} \\
\mathrm{PaO}_{2} \\
\mathrm{PaCO}_{2} \\
\mathrm{pH} \\
\mathrm{BE}\end{array}$ & $\begin{array}{c}12 \\
0 \cdot 98 \pm 0 \cdot 00 \\
48 \cdot 8 \pm 1 \cdot 2 \\
80 \cdot 0 \pm 2 \cdot 2 \dagger \\
7 \cdot 23(7 \cdot 11-7 \cdot 39) \dagger \ddagger \\
0 \cdot 0 \pm 0 \cdot 3\end{array}$ & $\begin{array}{c}12 \\
0 \cdot 99 \pm 0 \cdot 00 \\
51 \cdot 4 \pm 1 \cdot 3 \\
57 \cdot 7 \pm 4 \cdot 6 \dagger \\
7 \cdot 31(7 \cdot 16-7 \cdot 46)+\ddagger \\
-0 \cdot 6 \pm 1 \cdot 3\end{array}$ & $\begin{array}{c}11^{\star} \\
0 \cdot 99 \pm 0 \cdot 00 \\
51 \cdot 1 \pm 1 \cdot 4 \dagger \\
59 \cdot 2 \pm 4 \cdot 7 \\
7 \cdot 32(7 \cdot 24-7 \cdot 46) \ddagger \\
0 \cdot 6 \pm 0 \cdot 7\end{array}$ & $\begin{array}{c}11 \\
0 \cdot 95 \pm 0 \cdot 04 \\
73 \cdot 1 \pm 7 \cdot 7 \dagger \\
64 \cdot 5 \pm 3 \cdot 8 \\
7 \cdot 27(7 \cdot 07-7 \cdot 36) \ddagger \\
-0 \cdot 2 \pm 1 \cdot 9\end{array}$ \\
\hline
\end{tabular}

Mean values \pm 1 SEM (or range) are given.

*One infant collapsed while CIP was being set up and was mechanically ventilated.

$+P<0.05$.

$\ddagger$ Mean $p H$ derived by converting the mean hydrogen ion concentration expressed in nmol/l to $p H$. 


\section{TABLE III}

Outcome for infants in control and CIP-treated groups, and for the rest of the population of infants admitted during trial period

\begin{tabular}{|c|c|c|c|c|}
\hline & Control & CIP & $\begin{array}{l}\text { Other } \\
\text { infants }\end{array}$ & $\underset{\text { infants }}{\text { All }}$ \\
\hline $\begin{array}{l}\text { Not given CIP or MV } \\
\text { (no. of infants) } \\
\text { UCH } \\
\text { Referred } \\
\text { Total } \\
\text { Survived }\end{array}$ & $\begin{array}{l}5 \\
1 \\
6 \\
6\end{array}$ & $\begin{array}{l}0 \\
\mathbf{0} \\
\mathbf{0} \\
\mathbf{0}\end{array}$ & $\begin{array}{r}29 \\
8 \\
37 \\
37\end{array}$ & $\begin{array}{l}34 \\
9 \\
43 \\
43(100 \%)\end{array}$ \\
\hline $\begin{array}{l}\text { Treated by CIP } \\
\text { (no. of infants) } \\
\text { Electively } \\
\text { After MV } \\
\text { UCH } \\
\text { Referred } \\
\text { Total } \\
\text { Survived }\end{array}$ & $\begin{array}{l}0 \\
3 \\
2 \\
1 \\
3 \\
3\end{array}$ & $\begin{array}{r}12 \\
4 \\
7 \\
5 \\
12 \\
11\end{array}$ & $\begin{array}{r}0 \\
37 \\
8 \\
29 \\
37 \\
31\end{array}$ & $\begin{array}{l}12 \\
44 \\
17 \\
35 \\
52 \\
45(87 \%)\end{array}$ \\
\hline $\begin{array}{l}\text { Treated by MV } \\
\text { (no. of infants) } \\
\text { UCH } \\
\text { Referred } \\
\text { Total } \\
\text { Survived }\end{array}$ & $\begin{array}{l}5 \\
1 \\
6 \\
4\end{array}$ & $\begin{array}{l}4 \\
3 \\
7 \\
6\end{array}$ & $\begin{array}{l}11 \\
59 \\
70 \\
42\end{array}$ & $\begin{array}{l}20 \\
63 \\
83 \\
52(63 \%)\end{array}$ \\
\hline $\begin{array}{l}\text { Indications for } \mathrm{MV} \\
\text { (no. of infants) } \\
\mathrm{PaO}_{2}<35 \mathrm{mmHg} \\
\mathrm{F}_{\mathrm{y}} \mathrm{O}_{2}>0.95 \\
\text { Incipient collapse } \\
\text { Apnoea from birth } \\
\text { (UCH) } \\
\mathrm{MV} \text { in transit from } \\
\text { other hospitals }\end{array}$ & $\begin{array}{l}3 \\
3 \\
0 \\
0\end{array}$ & $\begin{array}{l}3 \\
4 \\
0 \\
0\end{array}$ & $\begin{array}{r}0 \\
8 \\
6 \\
56\end{array}$ & $\begin{array}{r}6 \text { (2 died) } \\
15 \text { (4 died) } \\
6 \text { ( } 3 \text { died) } \\
56 \text { (21 died) }\end{array}$ \\
\hline
\end{tabular}

MV, mechanical ventilation.

groups face masks or nasal cannulae were sometimes used to deliver CPAP after the endotracheal tube had been removed.

Mechanical ventilation. The indication for mechanical ventilation (Table III) in 3 of the 7 infants in the CIP group was a $\mathrm{PaO}_{2}<35 \mathrm{mmHg}$ $\left(27-34 \mathrm{mmHg}\right.$ ) with an $\mathrm{F}_{1} \mathrm{O}_{2}$ of $1 \cdot 0$. At the time 10,11 , and $12 \mathrm{cmH}_{2} \mathrm{O}$ of CIP were being used. 3 other infants were ventilated because of incipient collapse as defined above with CIPs of 6,10 , and $11 \mathrm{cmH}_{2} \mathrm{O}$. The remaining infant was ventilated for the same reason before CNP could be initiated. 3 of the 6 infants in the control group who needed ventilation were ventilated because of $\mathrm{PaO}_{2}$ values $<35 \mathrm{mmHg}$ (31-34 $\mathrm{mmHg}$ ), and the other 3 because of incipient collapse. The response to ventilation in the two groups was similar. Mean values for arterial blood gas tensions and acid-base status obtained just before and within 75 minutes after ventilation had started showed that $\mathrm{F}_{\mathrm{x}} \mathrm{O}_{2}$ fell from $0.97 \pm S E M \quad 0.01$ to $0.87 \pm 0.05$ (Student's paired 't' test, $\mathrm{P}<0 \cdot 05) ; \mathrm{PaO}_{2}$ rose from $40 \cdot 7 \pm 3 \cdot 2$
$\mathrm{mmHg}$ to $78 \cdot 7 \pm 10.5 \mathrm{mmHg}(\mathrm{P}<0 \cdot 005)$. $\mathrm{PaCO}_{2}$ tended to be lower $98 \cdot 5 \pm 10 \cdot 5$ vs $77 \cdot 6 \pm 10 \cdot 0$ $\mathrm{mmHg}$ (NS); $p \mathrm{H}$ higher $7 \cdot 13$ (range $6.91-7 \cdot 45$ ) vs $7 \cdot 20$ (range $6.95-7 \cdot 46$ ) (NS), and BE higher $-3 \cdot 7 \pm 3 \cdot 1$ vs $-2 \cdot 7 \pm 2 \cdot 4 \mathrm{mEq} / 1$ (NS). 2 infants (one in each group) received intravenous injections of $5 \%$ sodium bicarbonate solution immediately after ventilation had been initiated, and before arterial blood samples were taken for analysis. The infants in the CIP group were ventilated for $38 \cdot 6 \pm$ $4 \cdot 0$ hours, and the controls for $38 \cdot 3 \pm 10 \cdot 7$ hours. The mean ventilator settings used were similar in the two groups: peak airway pressure $25 \cdot 5 \pm 0 \cdot 8$ $\mathrm{cmH}_{2} \mathrm{O}$; end-expiratory pressure $3.5 \pm 0.5 \mathrm{cmH}_{2} \mathrm{O}$; inspiration : expiration ratio $1 \cdot 6 \pm 0 \cdot 2: 1$; and respiratory frequency $33 \cdot 7 \pm 1 \cdot 5$ cycles per minute. 2 control infants had to be ventilated again after recovery from HMD because of apnoea, apparently due to immaturity, and both survived.

Oxygen therapy. The length of time that the infants breathed an $\mathrm{F}_{1} \mathrm{O}_{2}>0.5$, and $>0.8$, is given in Table IV, together with the age at which

TABLE IV

Oxygen therapy in the control and CIP-treated group

\begin{tabular}{|c|c|c|c|}
\hline & Control & CIP & $\mathbf{P}$ \\
\hline $\begin{array}{r}\mathrm{F}_{\mathrm{r}} \mathrm{O}_{2} \\
\quad>0.8(\mathrm{~h}) \\
\quad>0.5(\mathrm{~h})\end{array}$ & $\begin{array}{r}61 \cdot 6 \pm 9 \cdot 0 \\
109 \cdot 7 \pm 9 \cdot 2\end{array}$ & $\begin{array}{l}25 \cdot 7 \pm 4 \cdot 6 \\
80 \cdot 6 \pm 8 \cdot 4\end{array}$ & $\begin{array}{l}<0.005 \\
<0.05\end{array}$ \\
\hline $\begin{array}{l}\text { Age when the } \\
\text { survivors were } \\
\text { breathing room } \\
\text { air spontaneously } \\
\text { (d) }\end{array}$ & $9 \cdot 3 \pm 1 \cdot 1$ & $9 \cdot 5 \pm 0 \cdot 8^{\star}$ & NS \\
\hline
\end{tabular}

*Excludes 2 infants who needed a period of mechanical ventilation for apnoea apparently due to immature control of breathing. $\mathrm{F}_{1} \mathrm{O}_{2}$, fractional inspired oxygen concentration.

they had recovered sufficiently to be breathing room-air spontaneously. The CIP group breathed high concentrations of oxygen for a shorter period than the controls (a difference which remains if only the survivors are considered). The age at which the infants were breathing air spontaneously was similar if the 2 control infants who required an additional period of ventilation are excluded. These 2 infants were breathing air at ages $3 \frac{1}{2}$ and 4 weeks, respectively.

Cause of death and complications of therapy. The 3 infants who died, 1 from the CIP group and 2 controls, were all born at 30 weeks of gestation and weighed 1200, 1290, and $1380 \mathrm{~g}$. 
They died at 30, 50, and 120 hours of age and all had intraventricular haemorrhages and the changes of HMD at necropsy. One infant in the CIP group was found to have a spontaneous pneumothorax at the time of entry to the trial, and one other infant who died had developed a pneumothorax either while being treated with $10 \mathrm{cmH}_{2} \mathrm{O}$ of CPAP or just after the start of mechanical ventilation. No control infants had pneumothoraces.

Pathogenic bacteria (Staphylococcus albus, Serratia marcescens, and Esch. coli) were grown from endotracheal aspirates in 2 of the CIP group and in 1 control. No proven infections occurred in the infants in either group during treatment of HMD, but 1 control who needed further mechanical ventilation developed a probable infection later as evidenced by a polymorphonuclear leucocytosis, and 1 control who had never been intubated or needed ventilatory support developed pneumonia at one week of age probably caused by Enterobacter cloacae. Both recovered after antibiotic treatment.

An infant in the CIP group, who was electively intubated and treated with CPAP but not ventilated, was readmitted with severe stridor at the age of 5 months, and found to have a laryngeal web and subglottic oedema which required a tracheostomy and separation of the vocal cords. He made an uneventful recovery with no residual evidence of airway obstruction.

Follow-up. All the infants are being seen regularly. When last seen at between 5 months and 2 years 10 months of age they were still too young for detailed developmental assessment but they seemed to be progressing normally. The control infant who had had pneumonia in the newborn period required 4 admissions to hospital with respiratory infections during the first year of life, but no others had any apparent respiratory problems.

Infants not entering the controlled trial. The outcome for the 107 infants who did not meet the criteria for entry to the trial is summarized in Tables I and II. 37 survived after breathing high concentrations of oxygen $\left(\mathrm{F}_{\mathrm{I}} \mathrm{O}_{2}>0.60\right)$ spontaneously without CIP or mechanical ventilation. The remaining 70 infants needed ventilation, in 62 cases because they were already being ventilated on arrival in the unit. 56 of these 62 infants had to be ventilated during their transfer from other hospitals and the other 6 infants were born in this hospital but did not establish spontaneous breathing. $80(75 \%)$ of the 107 infants survived the neonatal period. The usual cause of death in the 27 who died was intraventricular haemorrhage. 7 infants died later, 2 with tracheo-oesophageal fistulae, 1 with congenital heart disease, 2 apparently normal infants as cot deaths, and 2 with bronchopulmomary dysplasia. 1 of these latter 2 infants had inhaled large amounts of feed after apparently recovering from HMD. At follow-up one infant who had had haemorrhagic pulmonary oedema (Cole et al., 1973) as well as HMD had recovered from bronchopulmonary dysplasia by the age of 9 months. None of the remainder had any evidence of adverse pulmonary sequelae, but one had retrolental fibroplasia.

\section{Discussion}

Population and overall survival rate. Since the neonatal unit of this hospital is a referral centre for the North-East Thames Region, and accepts sick infants from other regions as well, the proportion of infants who were severely affected by their illness is likely to have been higher than in many other units. During the trial period 74 infants with severe HMD were accepted from 31 other hospitals within a radius of about 60 miles of this hospital. 56 were apnoeic, or in a very precarious state, and needed mechanical ventilation in transit as well as after arrival in the unit (Table I). They did not therefore qualify for entry to the trial. Conversely, infants born in this hospital were rarely sufficiently ill to reach our criteria for entry. For these reasons a total of 131 consecutive infants with severe HMD had to be admitted before two groups of 12 infants were collected who were suitable for the trial. $88 \%$ of the infants who were born in this hospital, and $69 \%$ of the referred infants survived the neonatal period, giving an overall survival rate of $77 \%$ (Table I).

Outcome of controlled trial. The object of the trial was to find out whether elective intervention with CIP conferred any benefits on infants with $\mathrm{HMD}$ whose $\mathrm{PaO}_{2}$ fell below $60 \mathrm{mmHg}$ while breathing an $\mathrm{F}_{1} \mathrm{O}_{2}>0 \cdot 95$. This indication for entry was stricter than criteria used in previous controlled trials (Rhodes and Hall, 1973; Fanaroff et al., 1973) and was chosen because our past experience (Reynolds, 1970) indicated that about $50 \%$ of infants with a $\mathrm{PaO}_{2}$ this low would require some form of ventilatory assistance.

The composition of the two groups of 12 infants in the controlled trial was similar (Tables I and II) and no difference in survival rate or in the number of infants requiring mechanical ventilation was found (Table I). We were unable therefore to show any important beneficial effect of intervening electively with CIP. It was possible though to 
show that $\mathrm{PaO}_{2}$ increased when CIP was started and that the CIP-treated group breathed high concentrations of oxygen for a shorter period than the control group. These findings confirm what has previously been shown by Rhodes and Hall (1973) and Fanaroff et al. (1973).

Complications of therapy in both groups were few, the most important one being a temporary tracheostomy because of damage to the upper airway in an infant electively intubated for CPAP. He might have recovered from the HMD without ventilatory assistance had he been left breathing an $\mathrm{F}_{\mathrm{r}} \mathrm{O}_{2}$ of 1.00 spontaneously and not intubated. This complication was unexpected and should be kept in perspective. A similar problem occurred in only one other infant during the past 5 years, and no serious damage to the larynx or trachea had been found at necropsy among infants dying in our unit after prolonged intubation (Reynolds and Taghizadeh, 1974).

Implications and conclusions. Continuous inflating pressure is an extremely effective therapeutic tool for the management of HMD (Gregory et al., 1971; Chernick and Vidyasagar, 1972; Rhodes and Hall, 1973; Kattwinkel et al., 1973; Fanaroff et al., 1973; Cumarasamy et al., 1973; Baum and Roberton, 1974; Dunn, 1974). Our finding that there was no difference in survival rate between the treated and control groups should not be interpreted as showing that elective intervention with CIP is contraindicated. It shows only that in a unit where complications following mechanical ventilation are unusual (Blake et al., 1973; Reynolds, 1975) the alternative approach, in which unlimited oxygen is given in the inspired gas in order to maintain an adequate $\mathrm{PaO}_{2}$ and mechanical ventilation is used when necessary, yields an equally high survival rate and no apparent difference in the incidence of adverse sequelae. The results might have been different in a unit where staff trained in resuscitation are not available at all times and experience with mechanical ventilation is limited.

The question of whether earlier intervention with CIP would have been followed by a higher survival rate in our total population of infants should be considered. During the study period, 21 infants were mechanically ventilated because of incipient collapse or because of $\mathrm{a} \mathrm{PaO}_{2}$ lower than $35 \mathrm{mmHg}$, 7 in the CIP-treated group, 6 in the control group, and 8 other infants (Table III). 6 of these 21 infants died. Assuming that all would have survived if CIP had been initiated at an early stage of their illness, then the survival rate of infants born in the hospital would have increased from $88 \%$ to $93 \%$, and for referred infants from $69 \%$ to $73 \%$, an overall increase in survival rate of $5 \%$, from $77 \%$ to $82 \%$. Similar calculations show that if, in the unlikely event of all the 21 infants ventilated because of a low $\mathrm{PaO}_{2}$ or incipient collapse surviving without needing ventilation if treated early, then the percentage of infants admitted requiring ventilation would have fallen from $63 \%$ (83 infants) to $47 \%$ (62 infants).

The indications for elective intervention with CIP remain unclear. Mainly because oxygen breathing has been implicated in the pathogenesis of bronchopulmonary dysplasia, many authors prefer to intervene in order to avoid the need to administer an $\mathrm{F}_{\mathrm{I}} \mathrm{O}_{2}>0.4-0.7$ (Chernick and Vidyasagar, 1972; Rhodes and Hall, 1973; Fanaroff et al., 1973; Kattwinkel et al., 1973; Cumarasamy et al., 1973; Baum and Roberton, 1974; Dunn, 1974). Yet 43 infants admitted during our study period survived who were treated with a high inspired oxygen concentration $\left(\mathrm{F}_{\mathrm{I}} \mathrm{O}_{2}>0.6\right)$ but needed neither CIP nor mechanical ventilation (Table III). None showed any ill effects. Elective intervention with CIP in these infants would have meant unnecessary treatment of $33 \%$ of the total population of infants. Serious or irreversible damage to the lung has never been described in infants with $\mathrm{HMD}$ who survive without ventilatory assistance, however much oxygen they have breathed, and evidence has been presented (Reynolds and Taghizadeh, 1974; Taghizadeh and Reynolds, 1976) that the main cause of bronchopulmonary dysplasia following this illness is trauma to the lung from the use of unnecessarily high peak airway pressures and respiratory frequencies during mechanical ventilation. We do not believe, therefore, that the case for intervening with CIP so as to keep the inspired oxygen concentration below some arbitrary level has yet been proved. A more cogent reason for early intervention might be to prevent progressive collapse of the lung which becomes so severe that very high airway pressures are required later to overcome it. All methods for delivering CIP have potential dangers (Chernick, 1973; Dunn, 1974; Baum and Roberton, 1974; Reynolds, 1975) which have to be weighed against their advantages, and further controlled trials seem to be indicated, particularly to test the effect of very early intervention with relatively innocuous froms of CIP such as face masks and nasal cannulae. We are currently engaged in such a trial.

There was no opportunity to consider elective intervention with CIP in $62(47 \%)$ of the infants admitted during our study period because they were already being ventilated on arrival in the unit 
(Table III). We conclude from this that in a regional referral centre with a severely affected population similar to ours, mechanical ventilation is likely to continue to be important in the management of infants with HMD. We have found CIP very useful in the weaning of infants from ventilators, but have no definite evidence that the period of ventilation is shortened thereby, or that the infants benefit from a period of weaning with CIP. We suspect, however, like others (Cumarasamy et al., 1973; Baum and Roberton, 1974), that both may be the case.

We are grateful to the medical and nursing staff of the Neonatal Unit for their devoted care of the infants; to Birthright for supporting G. M. D.; and to C. M. J. Bright for technical assistance.

\section{REFERENCES}

Adamson, T. M., Hawker, J. M., Reynolds, E. O. R., and Shaw, J. C. L. (1969). Hypoxemia during recovery from severe hyaline membrane disease. Pediatrics, 44, 168.

Barrie H. (1973). Continuous positive airway pressure for the respiratory distress syndrome. Lancet, $2,851$.

Baum, J. D., and Roberton, N. R. C. (1974). Distending pressure in infants with respiratory distress syndrome. Archives of Disease in Childhood, 49, 771.

Blake, A. M., Collins, L. M., Durbin, G. M., Hunter, N. J., Macnab, A. J., Reynolds, E. O. R., and Sellens, G. (1973). Simplified mechanical ventilation for hyaline-membrane disease. Lancet, 2, 1176 .

Caliumi-Pellegrini, G., Agostoni, R., Orzalesi, M., Nodari, S., Marzetti, G., Savignoni, P. G., and Bucci, G. (1974). Twin nasal cannula for administration of continuous positive airway pressure to newborn infants. Archives of Disease in Childhood, 49, 228.

Chernick, V. (1973). Hyaline-membrane disease-therapy with lung-distending pressure. New England fournal of Medicine, $289,302$.

Chernick, V., and Vidyasagar, D. (1972). Continuous negative chest wall pressure in hyaline membrane disease. Pediatrics, 49, 753.

Cole, V. A., Normand, I. C. S., Reynolds, E. O. R., and Rivers, R. P. A. (1973). Pathogenesis of hemorrhagic pulmonary edema and massive pulmonary hemorrhage in the newborn. Pediatrics, 51, 175.
Conway, M., Durbin, G. M., Parker, D., Reynolds, E. O. R., and Soutter, L. (1976). Continuous measurement of arterial oxygen tension using a polarographic electrode in infants. Pediatrics, 5.

Cumarasamy, N., Nüssli, R., Vischer, D., Dangel, P. H., and Duc, G. V. (1973). Artificial ventilation in hyaline membrane disease: the use of positive end-expiratory pressure and continuous positive airway pressure. Pediatrics, 51, 629.

Dunn, P. M. (1974). Continuous positive airway pressure using the Gregory box. Proceedings of the Royal Society of Medicine, 67, 245.

Fanaroff, A. A., Cha, C. C., Sosa, R., Crumrine, R. S., and Klaus, M. H. (1973). Controlled trial of continuous negative external pressure in the treatment of severe respiratory distress syndrome. fournal of Pediatrics, 82, 921.

Gregory, G. A., Kitterman, J. A., Phibbs, R. H., Tooley, W. H., and Hamilton, W. K. (1971). Treatment of the idopathic respiratory-distress syndrome with continuous positive airway pressure. New England fournal of Medicine, 284, 1333.

Herman, S., and Reynolds. E. O. R. (1973). Methods for improving oxygenation in infants mechanically ventilated for severe hyaline membrane disease. Archives of Disease in Childhood, 48, 612 .

Kattwinkel, J., Fleming, D., Cha, C. C., Fanaroff, A. A., and Klaus, M. H. (1973). A device for administration of continuous positive airway pressure by the nasal route. Pediatrics, 52, 131

Reynolds, E. O. R. (1970). Indications for mechanical ventilation in infants with hyaline membrane disease. Pediatrics, 46, 193.

Reynolds, E. O. R. (1974). Pressure wave-form and ventilator settings for mechanical ventilation in severe hyaline membrane disease. International Anesthesiology Clinics, 12, 259.

Reynolds, E. O. R. (1975). Management of hyaline membrane disease. British Medical Bulletin, 31, 18.

Reynolds, E. O. R., and Taghizadeh, A. (1974). Improved prognosis of infants mechanically ventilated for hyaline membrane disease. Archives of Disease in Childhood, 49, 505.

Rhodes, P. G., and Hall, R. T. (1973). Continuous positive airway pressure delivered by face mask in infants with the idiopathic respiratory distress syndrome: a controlled study. Pediatrics, 52, 1 .

Shaw, J. C. L. (1973). Parenteral nutrition in the management of sick low birthweight infants. Pediatric Clinics of North America, $20,333$.

Taghizadeh, A., and Reynolds, E. O. R. (1976). Pathogenesis of bronchopulmonary dysplasia following hyaline membrane disease. American fournal of Pathology, 82.

Correspondence to Dr. E. O. R. Reynolds, Department of Paediatrics, University College Hospital, London WC1. 